\title{
Influence of Heat Treatment on the Static Bending Strength of Spruce Wood
}

\author{
Eglė FATARAITÉ-URBONIENE * ${ }^{*}$ Inga JUODEIKIENE், Darius ALBREKTAS, \\ Simonas MEŠKAUSKAS
}

\author{
Department of Production Engineering, Kaunas University of Technology, Studentu str. 56, LT-3031 Kaunas, Lithuania \\ crossref http://dx.doi.org/10.5755/j01.ms.25.4.21522
}

Received 25 August 2018; accepted 06 June 2019

\begin{abstract}
The goal of this investigation was to find out influence of heat treatment at low temperatures on the Lithuanian spruce wood bending strength. The influence of heating temperature and duration on the strength of spruce wood during static bending has been investigated. The tests were carried out using samples with size of $20 \times 20 \mathrm{~mm}$ in cross-section and $300 \mathrm{~mm}$ in length. Density of samples varied from 460 up to $500 \mathrm{~kg} / \mathrm{m}^{3}$. The samples were heated at conditions close to those used during manufacturing process. Temperature was equal to $T=60,80,100$ and $120^{\circ} \mathrm{C}$ and heating duration was selected $\tau=24,48,72$ and 96 hours. The obtained results reveal that heating at relatively low temperatures, influences the strength of the spruce wood during bending. After the increase of both drying temperature and duration decrease of bending strength was found. The longer heating duration at lower temperatures results in less strength changes compare to those heated at higher temperatures for shorter duration. It was found that heating temperature is more significant technological parameter for spruce wood bending strength compare to those of heating duration.

Keywords: spruce wood, heat treatment, static bending.
\end{abstract}

\section{INTRODUCTION}

The spruce (Picea abies L) can be found in the mountains of Northern Europe and mountains of central and Southern Europe, covering the area from the Balkans to the Ural Mountains.

For example, in Lithuania, a spruce is one of the most common trees in the country's forests and occupies about $24 \%$ of the total area of the country's stands. The height of trees predominantly grown in stands is at an average of $27-29 \mathrm{~m}$ in height and diameter usually varies from 31 to $36 \mathrm{~cm}$. Spruce wood is yellowish-white, soft, low weight, it consists low amount of resin, relatively strong. Wood is used in building, furniture and cellulose manufacturing and the production of musical instruments [1]. Spruce wood is easy to process; it exhibits good adhesion properties. Besides, it has lower deformability and color changes (darkening) during drying process compare to those of pine wood. Due to that spruce wood is widely used for production timber frameworks, beams and roofs.

In order to improve some of wood properties (reduce moisture content and moisture absorption, increase the stability of the dimensions and shape, and to increase resistance to biological agents) wood is treated under drying or heating. That is usually followed by mechanical properties (strength) changes [2-4]. That is why, it is very important to know and predict the strength properties of wood used in structures.

At the moment, the wood modification is widely performed by heat treatment at high temperatures (from $T=150{ }^{\circ} \mathrm{C}$ to $280^{\circ} \mathrm{C}$ ) at duration which takes from a few ten minutes to several hours.

\footnotetext{
${ }^{*}$ Corresponding author. Tel.: + 00-37-0-610 04824.

E-mail address: egle.fataraite@ktu.lt (E. Fataraite-Urboniene)
}

The physical and mechanical properties of the modified wood depend on the temperature and duration of the heating [5].

Commonly, the influence of heat treatment on wood properties is complex and the intensity of the treatment depends on certain parameters such as treatment (heating) duration, temperature, heating medium, atmospheric pressure and wood moisture. It must be mentioned that chemical processes begin to occur in the wood at temperatures above $40-60{ }^{\circ} \mathrm{C}[6,7]$.

The heating parameters are selected depending on the type of wood, the type of process, the amount of moisture, and the characteristics we want to improve: dimensional stability or resistance to biological pests.

Thus, when heating wood at higher than drying temperatures, its durability and dimensional stability increase. However, mechanical properties after processing are getting worse $[8,9]$. Such kind of wood can not be used for supporting constructions.

Changes in the mechanical, physico-chemical properties of wood can also be observed when it is dried at low temperatures. The influence of drying temperatures on wood properties such as durability and dimensional stability will be improved less, but the decrease of mechanical properties usually is found less compare to those find after heating at higher temperatures.

There is sufficient information on variation of mechanical properties of spruce wood after heat treatment at high temperatures [10]. While both structural and mechanical properties changes after thermal treatment at low temperatures of hardwood such as beech, ash, oak are widely discussed by other authors [3]. Unfortunately, results obtained by different authors and explanation of obtained results up to now is a controversial issue. The explanations of obtained results are complicated due to the influence of many factors. Most important of them is high 
heterogeneity of structure, variety of wood species, both climate zone and growing place in the forest, methodology of selection of samples, etc.

The main goal of this investigation was to find out influence of heat treatment at low temperatures on the Lithuanian spruce wood bending strength.

\section{EXPERIMENTAL}

The spruce (Picea abies) wood from the eastern part of Lithuania (Moletai distrinct) was used for the investigation. Samples were prepared according to the ISO 3129: 2012 standard [11]. This standard specifies both the number of specimens required for one testing group and statistical analysis of the results. It has been found that 37 test groups are needed for one test group.

Boards from central spruce were left to dry for six months under open atmospheric conditions. After that workpieces with overlays were cut. After reaching $12-15 \%$ moisture, specimens with $20 \times 20 \mathrm{~mm}$ in cross section and $300 \mathrm{~mm}$ in length were cut. The prepared specimens were stored in a laboratory at a temperature of $T=20 \pm 2{ }^{\circ} \mathrm{C}$ and a relative humidity of $w=65 \pm 3 \%$. up to moisture of samples dropped down to $11-12 \%$. In the same environment specimens after heat treatment were conditioned for 2 months.

All samples were divided into 17 groups. Samples from 16 groups were heated for $\tau=24,48,72$ and 96 hours at temperature $T=60,80,100$ and $120^{\circ} \mathrm{C}$. Samples in group $17^{\text {th }}$ were left as control group without treatment. The groups of samples were tried to create as uniformly as possible in the density and visual features (quantity of heart wood and sapwood, the width of the ridge). The width of the ridge of the spruce wood samples in each group was $0.5-2.3 \mathrm{~mm}$.

The dimensions of the samples were determined using electronic caliper with accuracy of $0.01 \mathrm{~mm}$ (producer „Vogel GmbH \& Co“, Germany). Mass of samples was determined using jeweller scales by AND company, model HF-1200GD with accuracy of $0.01 \mathrm{~g}$. Spruce wood samples were heated in a laboratory heater (SNOL 58/350, producer SC „Snoltherm“, Lithuania) in which the temperature is maintained to within $\pm 1{ }^{\circ} \mathrm{C}$.

Bending strength was determined according to ISO 13061-3: 2014 standard [12]. Tests were carried out using universal testing machine Tinius Olsen H25KT, UK at upper head speed $4 \mathrm{~mm} / \mathrm{min}$.

During the one-point static bending test, the specimen was placed in the test machine so that the bending force acting on the radiant surface in the middle line of the sample (Fig. 1).

The ultimate strength in static bending $f_{\omega}$ at the moisture content, $\omega$, at the time of test was given, in MPa, according to the formula:

$$
f_{\omega}=\frac{3 \cdot F_{\max } \cdot l}{2 \cdot b \cdot h^{2}},
$$

where $F_{\max }$ is the breaking load, $\mathrm{N} ; l$ is the distance between the centres of the supports, $\mathrm{mm} ; b$ is the width of the test piece, $\mathrm{mm} ; h$ is the height of the test piece, $\mathrm{mm}$.

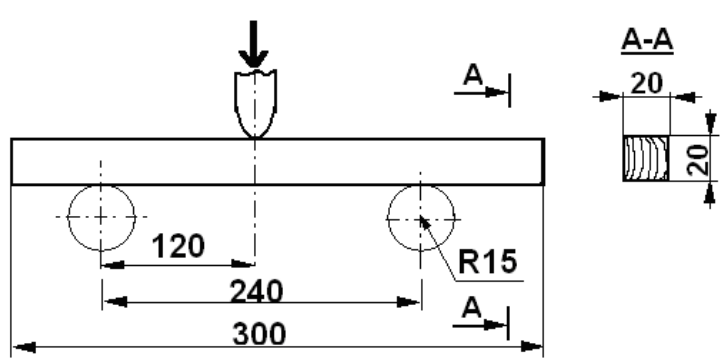

Fig. 1. Static bending scheme

When necessary, the ultimate strength in static bending $f_{\omega}$ shall be adjusted to at $12 \%$ moisture content to an accuracy of $1 \mathrm{MPa}$ according to the formula:

$$
f_{12}=f_{\omega}[1+\alpha(\omega-12)] \text {, }
$$

where $\alpha$ is the correction factor for moisture content $(0,04)$; $\omega$ is actual moisture content of the wood, $\%$.

The moisture and density of the samples were determined according to the methodology set out in standards ISO 13061-1: 2014 and ISO 13061-2: 2014 $[13,14]$.

The moisture content, $\omega$, of each test piece, as a percentage by mass, was calculated to an accuracy of $1 \%$ from the formula:

$$
\omega=\frac{m_{\omega}-m_{0}}{m_{0}} \cdot 100,
$$

where $m_{\omega}$ is the mass of the test piece before drying, $\mathrm{g} ; m_{0}$ is the mass of the test piece after drying, g.

The density $\rho_{\omega}$ of each test piece at the moisture content $\omega$ at the time of the test was given, in $\mathrm{kg} / \mathrm{m}^{3}$, by the formula:

$\rho_{b}=\frac{m_{\omega}}{a_{\omega} \cdot b_{\omega} \cdot l_{\omega}}=\frac{m_{\omega}}{V_{\omega}}$,

where $m_{\omega}$ is the mass of the test piece at moisture content $\omega, \mathrm{kg} ; a_{\omega}, b_{\omega}, l_{\omega}$ are the dimension of the test piece at moisture content $\omega, \mathrm{m} ; V_{\omega}$ is the volume of the test piece at moisture content $\omega, \mathrm{m}^{3}$.

\section{RESULTS AND DISCUSSION}

The density of spruce wood samples after heating at selected conditions was $\rho=460-485 \mathrm{~kg} / \mathrm{m}^{3}$ and humidity was $w=7.3-8.9 \%$. The density of unheated samples was $\rho=500 \mathrm{~kg} / \mathrm{m}^{3}$ and humidity was $w=11.8 \%$. The significant decrease of the moisture after heating leads on to the decrease of wood hygroscopicity $[15,16]$.

During one-point bending test the sample is leaked and in the upper part of the sample, compression stresses occurs, and in lower one tensile stresses dominate. The wood compression strength is significantly lower than the tensile strength, so the fracture of the sample begins at the compression (the upper) zone in the form of wrinkles, although almost invisible by eyes. Finally, the specimen decays in the tensile zone. At the beginning cracking or splitting of the edge fibers occur, and then the specimen is 
completely broken. The fracture mode can be used as parameter for characterization of wood quality (Fig. 2). In case of high quality, strong wood, fracture in tensile zone was uneven with sharp fragments (Fig. 2 a), while fracture zone of weak, low quality wood samples was more even, amplitude of fracture fragments was found low (Fig. 2 b).

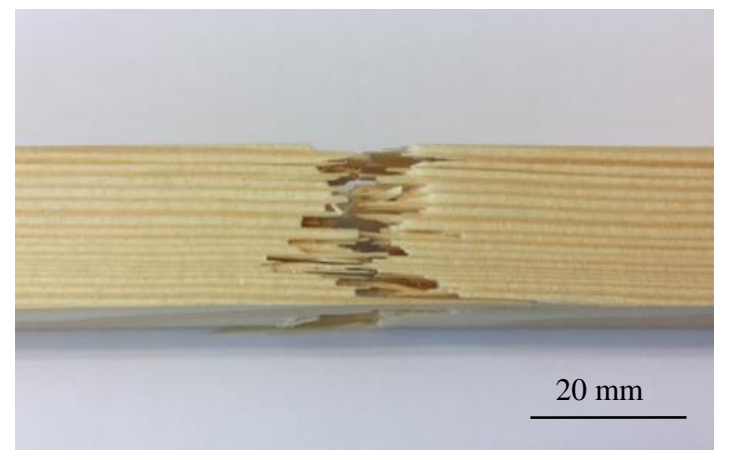

a

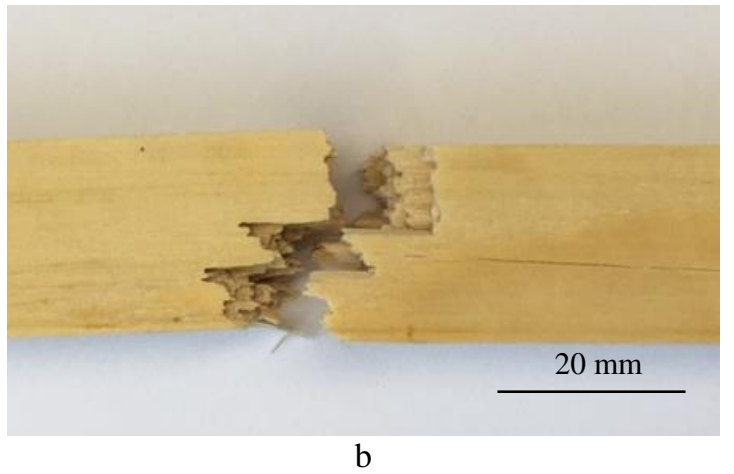

Fig. 2. Typical fracture zone for: $a$-high quality; b-weak quality wood samples

Results of bending test are presented in Table 1.

Table 1. Bending strength of spruce wood samples

\begin{tabular}{|c|c|c|c|c|c|}
\hline \multirow{2}{*}{ Duration, h } & \multirow{2}{*}{ Un-treated } & \multicolumn{5}{|c|}{ Temperature, ${ }^{\circ} \mathrm{C}$} \\
\cline { 3 - 6 } & & 60 & 80 & 100 & 120 \\
\hline \multicolumn{6}{|c|}{ Static bending strength, MPa } \\
\hline Untreated & 88.0 & - & - & - & - \\
\hline 24 & - & 82.7 & 82.0 & 78.3 & 77.4 \\
\hline 48 & - & 82.2 & 82.2 & 77.7 & 76.3 \\
\hline 72 & - & 82.2 & 81.6 & 79.0 & 74.9 \\
\hline 96 & - & 81.7 & 81.1 & 78.6 & 75.5 \\
\hline
\end{tabular}

Experimental results have revealed following tolerance of statistical parameters: group standard deviation was $s=(6.1-11.2) \%$, mean error of arithmetic mean $S_{\mathrm{r}}= \pm(1.4-2.1)$, coefficient of variation $V=(7.1-14.8) \%$, index of test precision, at a confidence level of 0.95 was $p=(3.5-5.2) \%$.

From Table 1 it is evident that the heat treatment reduces the spruce wood bending strength compared to those of untreated wood, the results indicate that at some temperatures heating duration is not dominant parameter influencing bending strength of samples. The strength of the heated samples at $80{ }^{\circ} \mathrm{C}$ slightly decreased only after heating more than 48 hours of heating. At a temperature of $100{ }^{\circ} \mathrm{C}$, it is no clear dependence between heating duration and bending strength. The greatest decrease in strength was observed for samples heated at $120^{\circ} \mathrm{C}$ for 72 hours.
Independently to the duration of the heating, the bending strength of the spruce wood after heat treatment at $60{ }^{\circ} \mathrm{C}$ decreased by $5.3-6.3 \mathrm{MPa}$, after heating at $80^{\circ} \mathrm{C}$ decreased in $6-6.9 \mathrm{MPa}$, at $100{ }^{\circ} \mathrm{C}$ decreased in $9.0-10.3 \mathrm{MPa}$, at a temperature of $120^{\circ} \mathrm{C}$ decrease of bending strength was found in $10.6-13.1 \mathrm{MPa}$.

With the increase of heating temperature after 24 hours of heat treatment bending strength decreases in the range of 5 to $10.6 \mathrm{MPa}$, after 48 hours of heat treatment decreased from 5.6 to $11.7 \mathrm{MPa}$, and from 5.8 to $13.1 \mathrm{MPa}$ for 72 hours. The longest heat treatment duration (96 hours) results on the decrease of bending strength from 6.3 down to $12.5 \mathrm{MPa}$.

It was found that bending strength loss at different heating duration has linear character and can be expressed using simple linear equation:

$f_{\omega}=a T+b$,

where $T$ is the heating temperature.

Regression coefficients of this equation are presented in Table 2. Evident that it is strong relation between experimental and approximation results (value of determination coefficient $R^{2}$ is very close to 1 ). The obtained simple mathematical model can be useful for practical purposes to predict strength of heat treated samples or during selection heat treatment regimes.

Table 2. Parameters of Eq. 5

\begin{tabular}{|c|c|c|c|}
\hline \multirow{2}{*}{ Duration, $\mathrm{h}$} & \multicolumn{3}{|c|}{ Equation parameters } \\
\cline { 2 - 4 } & $\mathrm{a}$ & $\mathrm{b}$ & $\mathrm{R}^{2}$ \\
\hline 24 & -0.1078 & -89.876 & 0.972 \\
\hline 48 & -0.117 & -90.169 & 0.9587 \\
\hline 72 & -0.1225 & -90.45 & 0.966 \\
\hline 96 & -0.118 & -89.997 & 0.9746 \\
\hline
\end{tabular}

Fig. 3 shows percentage decrease in the bending strength of heat treated spruce wood compare to untreated samples. Already after wood heating at $60{ }^{\circ} \mathrm{C}$ for 24 hours, it is possible to observe a decrease in bending strength. It can also be seen from the data provided that the heating over longer duration at lower temperatures did not produce the same results as heat treatment at higher temperatures for a shorter duration. The bending strength of the spruce wood samples after heating for 96 hours at $120^{\circ} \mathrm{C}$ was $2.45 \%$ lower than those heated at $120{ }^{\circ} \mathrm{C}$ for 24 hours. However, the strength of the wood samples heated at $120{ }^{\circ} \mathrm{C}$ for 96 hours was $7.58 \%$ lower than those of the heated at $60{ }^{\circ} \mathrm{C}$ for 96 hours. Therefore, it can be accepted that the heating temperature has a greater influence on the mechanical properties of the wood than the heating duration [9].

Meanwhile, the effort to find out one common simple mathematical model:

$\Delta f=a \tau+b$,

where $\tau$ is the heating duration, describing bending strength changes at constant temperature varying heating duration was not so successful. Regression coefficients of this equation is presented in Table 3 . Values of coefficient of determination $R^{2}$ only at temperature of $T=60{ }^{\circ} \mathrm{C}$ shows high dependence between model and experimental results, 
while in other cases relation between mathematical and experimental results was in medium strength (at temperature of $T=120^{\circ} \mathrm{C}$ and $80^{\circ} \mathrm{C}$ ) or weak (at temperature of $T=100{ }^{\circ} \mathrm{C}$ ).

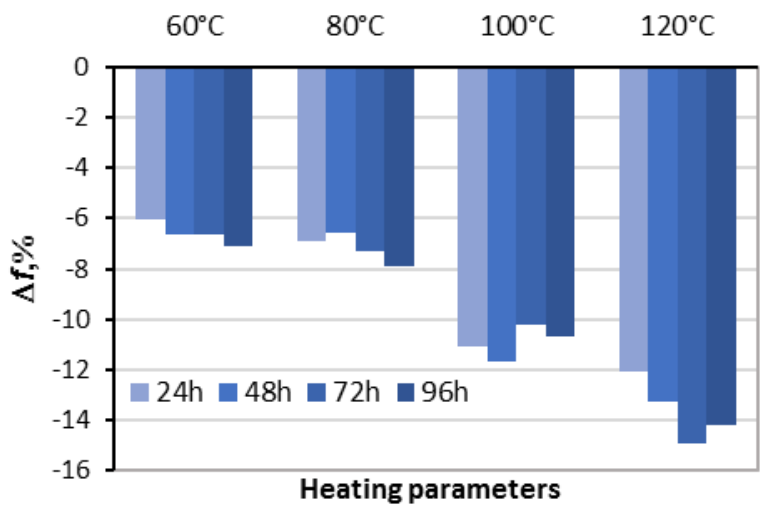

Fig. 3. Percentage decrease of spruce wood static bending strength after heat treatment

Table 3. Parameters of Eq. 6

\begin{tabular}{|c|c|c|c|}
\hline \multirow{2}{*}{ Temperature, ${ }^{\circ} \mathrm{C}$} & \multicolumn{3}{|c|}{ Equation parameters } \\
\cline { 2 - 4 } & $a$ & $b$ & $\mathrm{R}^{2}$ \\
\hline 60 & -0.0001 & -0.0574 & 0.9 \\
\hline 80 & -0.0002 & -0.0619 & 0.7696 \\
\hline 100 & -0.0001 & -0.1153 & 0.2689 \\
\hline 120 & -0.0003 & -0.1159 & 0.7186 \\
\hline
\end{tabular}

These results indicate complexity and confirm importance of treatment regimes on bending strength of spruce wood samples. The obtained results coincide well with the results obtained by other investigators $[6,7]$.

Wood mechanical properties changes after heat treatment is highly dependent on the structural changes of the wood. It is determined that after temperature of wood reaches $T=50-60{ }^{\circ} \mathrm{C}$ structural changes of wood begin, while degradation of lignin and cellulose starts only at $T=100{ }^{\circ} \mathrm{C}$. Although the mass loss starts to appear at $T=150-180^{\circ} \mathrm{C}$ [8]. According to other researchers, hemicellulose, which combines lignin and cellulose, is the most hygroscopic and least heat-resistant wood component and begins to degrade at relatively low temperatures, usually at $T=60^{\circ} \mathrm{C}$. Mainly due to the degradation of this element, the mechanical properties of wood start to worsen $[9,17]$. This suggestion can be used to explain the fact due to which the spruce wood bending strength starts to decrease after heat treatment of the wood at temperature of $T=60^{\circ} \mathrm{C}$ for $\tau=24$ hours. However, during exploitation it should be evaluated that the artificially heat treated wood hygroscopicity is lower than those of untreated [15]. This means that the moisture absorption during exploitation of treated wood will be lower and its strength will be higher, because the strength of the lower moisture wood is higher. Therefore, using spruce wood as a structural one, it is necessary to evaluate not only the drying parameters but also the air parameters of the environment in which it will be used.

\section{CONCLUSIONS}

The influence of heat treatment regimes at relatively low, near-drying temperatures $\left(T=60-120^{\circ} \mathrm{C}\right)$ on the mechanical properties of spruce wood from the Eastern part of Lithuania have been investigated. It was found that bending strength of thermal treated samples was decreased compared to that of untreated. The increase of treatment temperature and duration intensify this process. The temperature effect at the same treatment duration has clear expressed linear character, while attempt to find out simple mathematical relation between treatment duration and bending strength loss at the constant temperature was unsuccessful. The obtained results suggest that thermal treatment of spruce wood samples at lower temperature for longer duration allows to achieve higher bending strength in comparison to samples treated at higher temperatures for a shorter duration.

\section{REFERENCES}

1. Navasaitis, M., Ozolinčius, R., Smaliukas, D., Balevičienè, J. Lietuvos dendroflora. Kaunas: Lutute, 2003: pp. 576. (in Lithuanian).

2. Widmann, R., Fernandez-Cabo, J. L., Steiger, $R$. Mechanical Properties of Thermally Modified Beech Timber for Structural Purposes European Journal of Wood and Wood Products. 70 (6) 2012: pp. $775-784$. https://doi.org/10.1007/s00107-012-0615-x

3. Campean, M., Marinescu, I., Ispas, M. Influence of Drying Temperature upon Some Mechanical Properties of Beech Wood Holz als Roh- und Werkstoff 65 (6) 2007: pp. $443-448$. https://doi.org/10.1007/s00107-007-0193-5

4. Uribe, B., Ayala, O. Characterization of Three Wood Species (Oak, Teak and Chanul) before and after Heat Treatment Journal of the Indian Academy of Wood Science 12 (1) 2015: pp. 54-62.

https://doi.org/10.1007/s13196-015-0144-4

5. Kacikova, D., Kacik, F., Cabalova, I., Durkovic, J. Effects of Thermal Treatment on Chemical, Mechanical and Colour Traits in Norway Spruce Wood Bioresource Technology 144 2013: pp. 669-674. https://doi.org/10.1016/j.biortech.2013.06.110

6. Yildiz, S., Gezer, E.D., Yildiz, U.C. Mechanical and Chemical Behaviour of Spruce Wood Modified by Heat Building and Environment 41 (12) 2006: pp. 1762-1766. https://doi.org/10.1016/j.buildenv.2005.07.017

7. Sun, B., Wang, Z., Liu, J. Changes of Chemical Properties and the Water Vapour Sorption of Eucalyptus pellita Wood Thermally Modified in Vacuum Wood Science 63 (2) 2017: pp. $133-139$. https://doi.org/10.1007/s10086-016-1601-4

8. Oltean, L., Teischinger, A., Hansmann, Ch. Influence of Low and Moderate Temperature Kiln Drying Schedules on Specific Mechanical Properties of Norway Spruce Wood Wood and Wood Products 69 (3) 2011: pp. 451-457. https://doi.org/10.1007/s00107-010-0467-1

9. Rautkar, L., Honkanen, J., Hill, C., Ridley-Ellis, D., Hughes, M. Mechanical and Physical Properties of Thermally Modified Scots Pine Wood in High Pressure Reactor under Saturated Steam at 120,150 and $180^{\circ} \mathrm{C}$ Wood and Wood Products 72 (1) 2014: pp. 33-41. https://doi.org/10.1007/s00107-013-0749-5

10. ThermoWood ${ }^{\circledR}$ Handbook. International ThermoWood Association, 2003. p.66 (reached on https://asiakas.kotisivukone.com/files/en.thermowood.palvel ee.fi/downloads/tw_handbook_080813.pdf, 10 August 2018). 
11. ISO 3129:2012 Wood-Sampling methods and general requirements for physical and mechanical testing of small clear wood specimens.

12. ISO 13061-3:2014 Physical and mechanical properties of wood-Test methods for small clear wood specimensPart 3: Determination of ultimate strength in static bending.

13. ISO 13061-1:2014 Physical and mechanical properties of wood-Test methods for small clear wood specimensPart 1: Determination of moisture content for physical and mechanical tests.

14. ISO 13061-2:2014 Physical and mechanical properties of wood-Test methods for small clear wood specimens Part 2: Determination of density for physical and mechanical tests
15. Juodeikienè, I. Influence of Thermal Treatment on the Hygroscopicity and Dimensional Stability of Oak Wood Materials Scscience (Medžiagotyra) 19 (1) 2013: pp. $51-55$.

http://dx.doi.org/10.5755/j01.ms.19.1.3825

16. Esteves, B., Pereira, H. Wood Modification by Heat Treatment BioResources 4 (1) 2009: pp. 370-404.

17. Tjeerdsma, B., Boonstra, M., Pizzi, A., Tekely, P., Militz, H. Characterization of Thermally Modified Wood: Molecular Reasons for Wood Performance Improvement Holz als Roh-und Werkstoff 56 1998: pp. 149-153. https://doi.org/10.1007/s001070050 